\title{
Antipili Antibody Affords Protection against Experimental Ascending Pyelonephritis
}

\author{
Fredric J. Silverblatt and L. Steven Cohen, Infectious Disease Service, \\ Sepulveda Veterans Administration Hospital, Sepulveda, California 91343
}

\begin{abstract}
A B S T RA C T The ability of antipili antibody to prevent ascending urinary tract infection was investigated in rats. One group of rats was immunized passively with rabbit antisera to purified pili and challenged by intravesicular inoculation of $5 \times 10^{7}$ heavily piliated Escherichia coli. Only 2 of 14 immunized animals developed cortical abscesses as compared to 13 of 15 control rats given normal rabbit serum $(P=0.0001)$. The mean log titer of bacteria in the kidneys of the immunized rats was 0.85 vs. 6.08 in the controls $(P<0.005)$. A second group was actively immunized with pili. 3 of $16 \mathrm{im}$ munized animals became infected as compared to 10 of 15 controls $(P=0.01)$. The mean log titers were 2.13 and 4.54 , respectively $(P<0.01)$. A third group was passively immunized and challenged with a strain that had different $\mathrm{O}, \mathrm{K}$, and $\mathrm{H}$ antigens but shared pili antigens. Abscesses occurred in 4 of 15 immunized animals as compared to 13 of 15 controls $(P=0.001)$. The mean $\log$ titers were 2.37 and 5.63 , respectively $(P<0.005)$. These results indicate that antipili antibody protects rats against ascending urinary tract infection.
\end{abstract}

\section{INTRODUCTION}

There is increasing evidence that colonization of the urogenital epithelium is an essential step in the pathogenesis of ascending urinary tract infection (UTI). ${ }^{1}$ Colonization of the vaginal vestibule commonly precedes infection of the bladder (1) and women who are prone to recurrent UTI are more often colonized with potential pathogens than are normal women (2). Two defects have been identified in the host defenses of infection-prone women that might account for their propensity for colonization: the absence of antibody in

Presented in part at the Western Section of the American Federation for Clinical Research, Carmel, Calif., February 1979, and published in abstract form. 1979. Clin. Res. 27: 43A.

Received for publication 13 March 1979 and in revised form 23 April 1979.

${ }^{1}$ Abbreviation used in this paper: UTI, urinary tract infection. the vaginal fluid to the colonizing strain (3) and an enhanced ability of uropathogens to adhere to their vaginal epithelial cells (4).

The common pili of gram-negative organisms have been shown to mediate bacterial attachment to the surface of uroepithelial cells (5). Additional reports have linked the presence of pili with the ability of an organism to cause UTI in humans (6) and experimental animals (7). As antipili antibody is known to block bacterial attachment to epithelial cells (8) we undertook to determine whether acquisition of immunity to pili would prevent ascending UTI in rats.

\section{METHODS}

Bacteria. Two clinical isolates of $E$. coli were used for all studies: EC 3781 (018 a,c:Kl: H 7) and EC 346 (0.25:K negative: $\mathrm{H} \mathrm{1)} .^{2}$

Purification of pili. Pili were purified by a modification of the method of Brinton (6). Heavily piliated bacteria were depiliated by mechanical agitation, and the pili precipitated with $45 \%$ ammonium sulfate. The pili were subsequently purified by differential and sucrose density centrifugation and repetative precipitation with $1 \mathrm{M}$ magnesium chloride.

Evaluation of the purity of isolated pili. Sodium dodecyl sulfate-polyacrylamide gel electrophoresis was done by the method of Laemmli (9). Isolated pili were negatively stained with $0.5 \%$ uranyl acetate by an agar diffusion method (10). Agar gel double diffusion was performed according to the method of Ouchterlony and Nilsson (11). Immune electron microscopy of antibody-treated bacteria was performed with ferritin-conjugated goat anti-rabbit IgG (Miles Laboratories, Inc., Elkhart, Ind.). The presence of pyrogenic amounts of endotoxin was determined by the Limulus lysate amoebocyte assay (Mallinckrodt Inc., St. Louis, Mo.).

Antipili antiserum. Rabbits were injected with $200 \mu \mathrm{g}$ of pili emulsified in complete Freund's adjuvant. At 6 and 7 wk an additional $200 \mu \mathrm{g}$ of pili suspended in saline were administered intravenously. When maximum agglutinating titers were achieved, rabbits were exsanguinated, the serum separated, heated at $56^{\circ} \mathrm{C}$ for $30 \mathrm{~min}$, and stored at $-90^{\circ} \mathrm{C}$. The agglutinating titers of the antibody was assessed by observing aggregation of whole organisms or isolated pili.

Immunization of rats. For passive immunization, rats were

${ }^{2} E$. coli strains were serotyped by Dr. Donald Brenner of the National Center for Disease Control, Atlanta, Ga. 
injected intravenously with $0.5 \mathrm{ml}$ of rabbit antipili serum. Controls received normal rabbit serum. Rats were actively immunized by intradermal injection of $100 \mu \mathrm{g}$ of purified pili emulsified with complete Freund's adjuvant. After 4 wk they received an additional $100 \mu \mathrm{g}$ intravenously. For controls, bovine serum albumin was substituted for the pili. Passively immunized rats were challenged with bacteria $24 \mathrm{~h}$ after administration of antiserum and actively immunized animals were challenged when maximal serum agglutinating titers were achieved.

Experimental infection. Ascending infection was induced by the transiently ligated ureter method of Brooks et al. (12). Approximately $5 \times 10^{7}$ colony-forming units of a 24-h growth of heavily piliated bacteria contained in $0.5 \mathrm{ml}$ normal saline were injected into the bladder. Animals were sacrificed after $7 \mathrm{~d}$ and the presence of renal cortical abscesses ascertained by visual inspection. The kidneys were homogenized in saline and after appropriate dilution, an aliquot of the homogenate was suspended in melted agar for enumeration of the number of colony-forming units.

\section{RESULTS}

The final preparations of the pili were pure by the following criteria. No contamination was observed by darkfield examination or negative staining electron microscopy. A single band was obtained with sodium dodecyl sulfate-polyacrylamide gel electrophoresis (Fig. 1). With agar gel double diffusion, a single precipitation line formed between the pili and antisera raised in rabbits to the homologous strain. Antisera to purified pili (EC 3781) formed a precipitation line to the pili of both EC 3781 and EC 346 (Fig. 2). Immune electron microscopy with ferritin-conjugated anti-IgG confirmed that the antisera antibody had specificity for the pili alone. Numerous ferritin molecules were seen to be

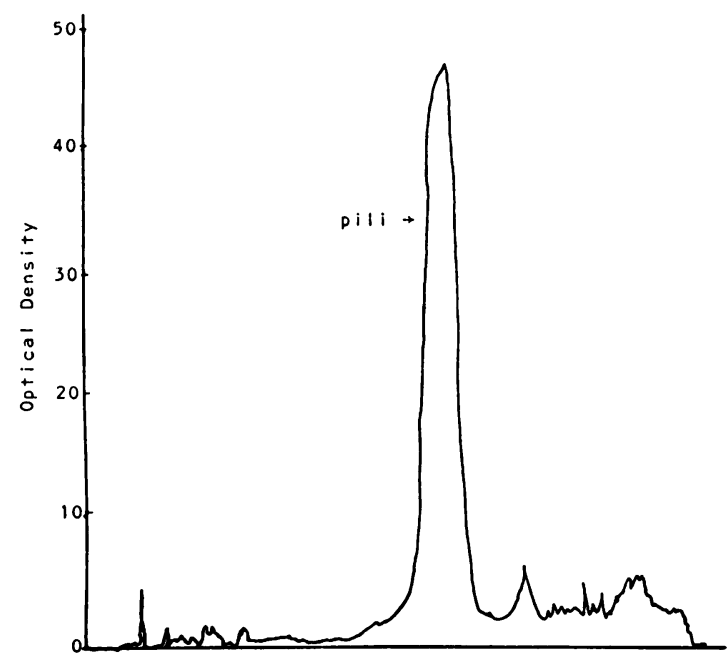

Figure 1 Densitometric tracing of sodium dodecyl sulfate polyacrylamide gel electrophoresis of purified $E$. coli pili. $50 \mu \mathrm{g}$ of pili protein were applied to the gel. The gel was stained with Coomassie Blue.

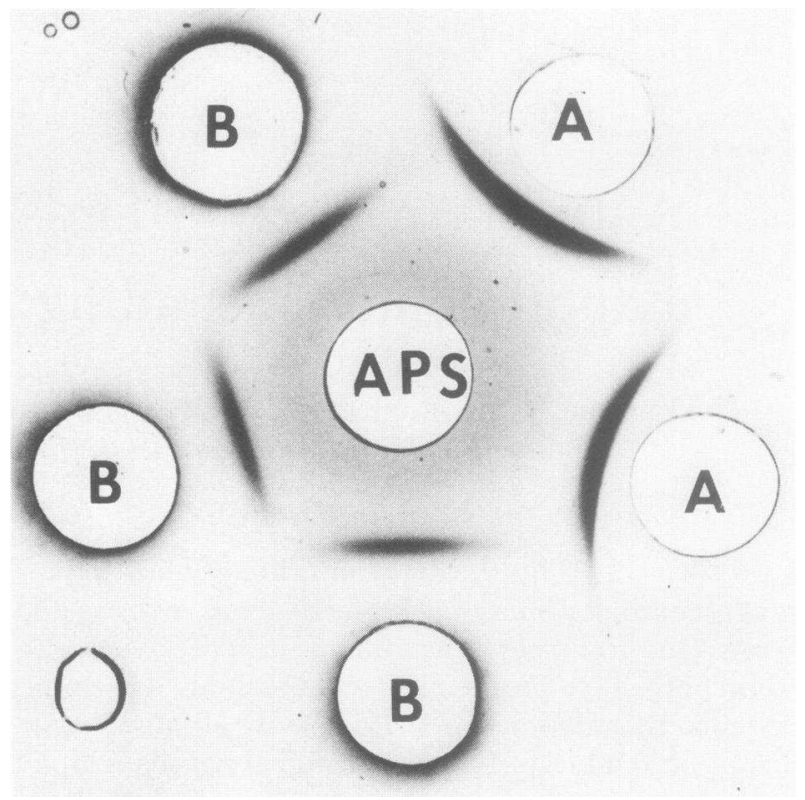

Figure 2 Agar-gel double diffusion patterns of anti-EC 3781 pili sera to the purified pili of EC 3781 and EC 346. APS, anti-EC 3781 pili sera; A, EC 3781 pili; B, EC 346 pili. Gels were incubated for $48 \mathrm{~h}$ and stained with Coomassie Blue.

attached to the pili of EC 3781 bacteria that had been incubated with anti-EC 3781 pili sera. Virtually no ferritin was associated with the flagella or nonpiliated bacterial surface (Fig. 3). Antibodies to the pili of EC 3781 also bound selectively to the pili of EC 346 as well, confirming that the pili of these two strains, shared antigenic determinants. The limulus lysate assay was negative indicating that less than pyrogenic amounts of endotoxin were present in the purified pili.

The mean reciprocal agglutinating titer of the serum of passively and actively immunized rats before bacterial challenge was 1024 and 512 , respectively. The protective effect of antipili serum for ascending infection is depicted in Table I. It can be seen that significantly fewer passively immunized rats developed cortical abscesses than unimmunized controls. Difference in mean bacterial titers paralleled the morphological observations. Protection was also achieved with active immunization. Animals passively protected with anti-EC 3781 pili sera were protected against challenge with EC 346 as well.

\section{DISCUSSION}

This study has shown that acquisition of immunity to the pili of $E$. coli protected rats from ascending $E$. coli UTI. As antibodies to $O$ (13), K (13), and $H$ (14) antigens are known to confer similar protection, it was deemed essential, in the present experiment, to exlcude rigor- 

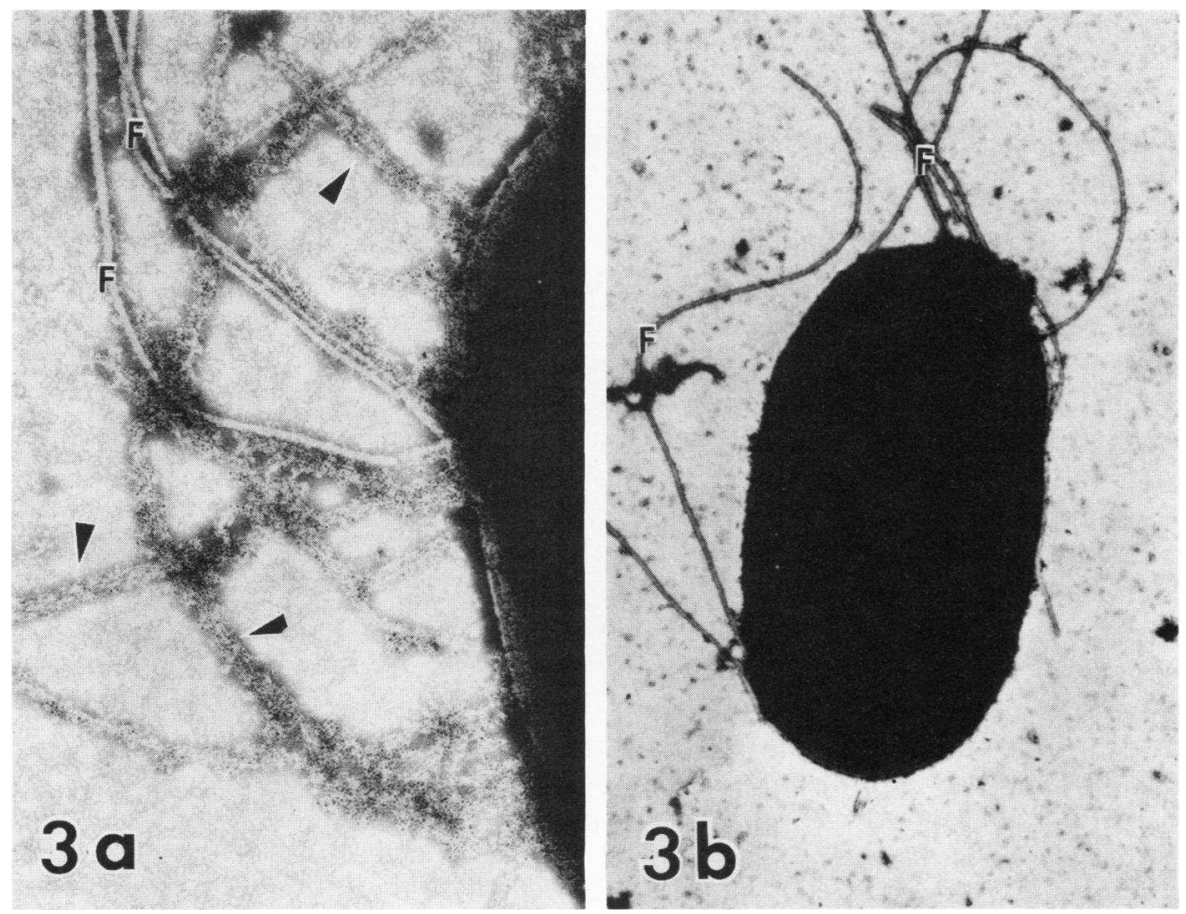

FIGURE 3 Ultrastructural localization of anti-EC 3781 pili on the surface of EC 3781 bacteria. The presence of the antibodies was detected with ferritin-conjugated anti-IgG. Ferritin molecules (black dots) can be seen overlying the pili (arrows) but not the flagella (F) nor the nonpiliated bacterial cell wall. (a) A portion of the surface of a heavily piliated organism. $\times 57,000$. (b) A nonpiliated organism devoid of ferritin molecules. $\times 24,000$.

ously their potential contribution. Three lines of evidence lend confidence to the conclusion that antipili antibody alone was responsible for the protective effects observed. First, the pili used for immunization were pure by generally accepted criteria (8). Second, immune electron microscopy confirmed that antipili antibody bound only to the pili themselves and not to any other surface structure. Last, animals immunized

TABLE I

Effect of Antipili Antibody on Outcome of Ascending E. coli UTI in Rats

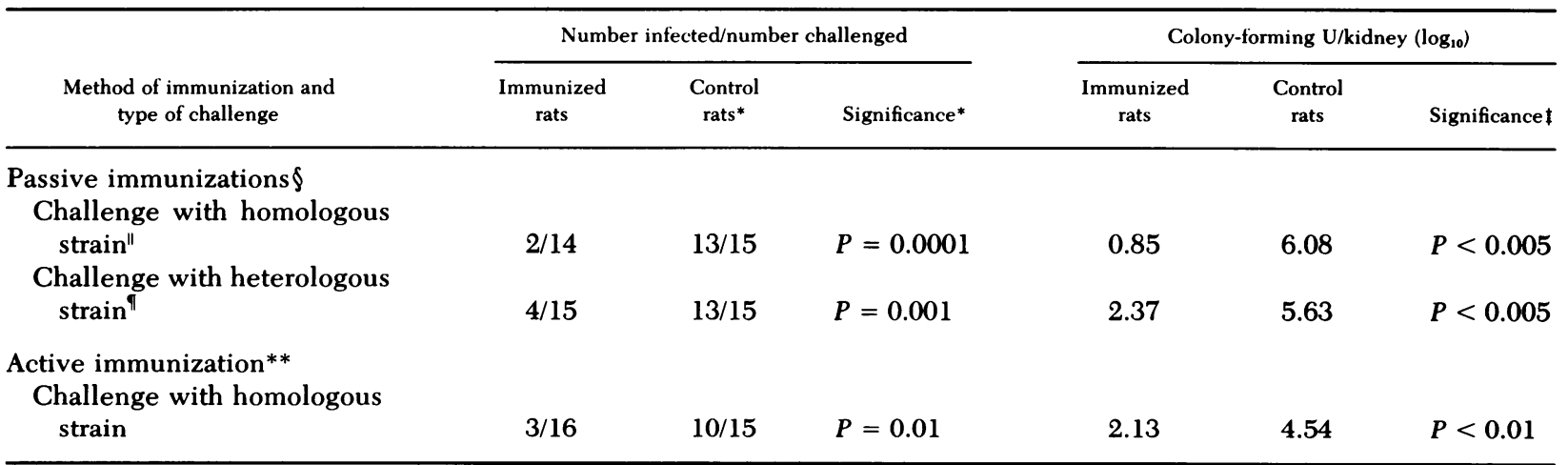

* Fischer's exact test.

I Student's $t$ test.

$\S$ Rats immunized with $0.5 \mathrm{ml}$ of rabbit anti-EC 3781 pili antiserum. Controls received $0.5 \mathrm{ml}$ of normal rabbit serum.

$115 \times 10^{7}$ EC 3781 bacteria inoculated intravesicularly.

$5 \times 10^{7}$ EC 346 bacteria inoculated intravesicularly.

** Immunized rats received EC 346 pili. Controls, bovine serum albumin. 
against the pili of EC 3781 were afforded significant protection against challenge with EC 346 , a strain that differed from EC 3781 with regard to the $\mathrm{O}, \mathrm{K}$, and $\mathrm{H}$ antigens but that shared pili antigens.

The fact that antipili antibodies reduced the rate of infection is additional, albeit indirect, evidence that pili are important virulence factors in ascending UTI. Pili are believed to assist bacteria in adhering to the surface of epithelial cells $(5,8)$. Antipili antibody has been shown to block adherence in vitro $(8)$ and presumably a similar mechanism may have been responsible for the protective effect of immunization. In this regard, recent observations indicate that antipili antibody did not promote the ingestion of piliated E. coli by human leukocytes (unpublished results).

Pili-based vaccines have recently been reported to prevent enterotoxigenic diarrhea in piglets (15). The results of the present study suggest that pili may prove effective for immune prophylaxis of UTI as well. The use of pili may overcome objections that have impeded development of vaccines employing other components of the bacterial surface. For example, $\mathrm{K}$ antigens are poor immunogens (13) and although certain $O$ groups predominate among strains of $E$. coli isolated from the urinary tract, there are more than $140 \mathrm{O}$ antigen groups. We have recently examined the pili of an additional three urinary tract strains of $E$. coli and found considerable antigenic cross reactivity. This suggests that the range of pili immunotypes may be more restricted than $\mathrm{O}$ groups. If so, it would simplify the composition of a potential vaccine.

Finally, it should be noted that in the present study bacteria were injected directly into the bladder. As a result we could not evaluate whether systemic immunity to pili prevents periurethral colonization, an important initial event in the pathogenesis of human infection (1). Therefore, additional studies are needed to determine whether antipili antibody is secreted into the urine and vaginal secretions in sufficient concentration to block colonization of this surface.

\section{ACKNOWLEDGMENTS}

These studies were supported by the Medical Research Service of the Veterans Administration and by U. S. Public Health Service grant Am-17991.

\section{REFERENCES}

1. Stamey, T. A., M. Timothy, M. Millar, and G. Mihara. 1971. Recurrent urinary tract infections in adult women. The role of introital enterobacteria. Calif. Med. 115: 1-19.

2. Stamey, T. A., and C. C. C. Sexton. 1975. The role of vaginal colonization with Enterobacteriaceae in recurrent urinary infections. J. Urol. 113: 214-217.

3. Stamey, T. A., N. Wehner, G. Mihara, and M. Condy. 1978. The immunological basis of recurrent bacteriuria: role of cervicovaginal antibody in enterobacterial colonization of the introital mucosa. Medicine (Baltimore). 57: 47-56.

4. Fowler, J. E., and T. A. Stamey. 1977. Studies of introital colonization in women with recurrent urinary infection VII. The role of bacterial adherence. J. Urol. 117: 472-476.

5. Svanborg-Eden, C., and L. A. Hansson. 1978. Escherichia coli pili as possible mediators of attachment to human urinary tract epithelial cells. Infect. Immun. 21: 229-237.

6. Brinton, C. C., Jr. 1965. The structure, function, synthesis and genetic control of bacterial pili and a molecular model for DNA and RNA transport in gram negative bacteria. Trans. N. Y. Acad. Sci. 27: 1003-1054.

7. Silverblatt, F. J. 1974. Host-parasite interactions in the rat renal pelvis. A possible role for pili in the pathogenesis of pyelonephritis. J. Exp. Med. 140: 1696-1711.

8. Salit, I. E., and E. C. Gotschlich. 1977. Type I Escherichia coli pili: characterization of binding to monkey kidney cells. J. Exp. Med. 146: 1182-1194.

9. Laemmli, U. K. 1970. Cleavage of structural proteins during the assembly of the head of bacteriophage T4. $\mathrm{Na}$ ture (Lond.). 227: 680.

10. Kelen, A. E., A. E. Hathaway, and D. A. McLeod. 1971. Rapid detection of Australian ISH antigen and antibody by a simple and sensitive technique of immunoelectronmicroscopy. Can. J. Microbiol. 17: 993-1000.

11. Ouchterlony, O., and L. A. Nilsson. 1978. Immunodiffusion and immunoelectrophoresis. In Handbood of Experimental Immunology. D. W. Weir, editor. Blackwell, Oxford and Edinburg, Oxford, England (1973). 3rd edition. Chapter 19: 1-43.

12. Brooks, S. J. D., J. M. Lyons, and A. I. Braude. 1974. Immunization against retrograde pyelonephritis I. Production of an experimental model of severe ascending Escherichia coli pyelonephritis without bacteremia in rats. Am. J. Pathol. 74: 345-358.

13. Kaijser, B., and S. Olling. 1973. Experimental haematogenous pyelonephritis due to Escherichia coli in rabbits: the antibody response and its protective capacity. J. Infect. Dis. 128: 41-49.

14. Pazin, G. J., and A. I. Braude. 1974. Immobilizing antibodies in urine. II. Prevention of ascending spread of Proteus mirabilis. Invest. Urol. 12: 129-133.

15. Nagy, B., H. W. Moon, R. E. Isaacson, C. To, and C. C. Brinton. 1978. Immunization of suckling pigs against enteric enterotoxigenic Escherichia coli infection by vaccinating dams with purified pili. Infect. Immun. 21: 269-274. 